\title{
Work-in-Progress - Self-Directed Learning and Motivation in a Project-based Learning Environment
}

\author{
Trevor S. Harding ${ }^{1}$, Linda Vanasupa ${ }^{2}$, Richard N. Savage ${ }^{3}$, and Jonathan D. Stolk ${ }^{4}$
}

\begin{abstract}
Self-directed learning is a key competency in life-long learning, an outcome often cited for engineering education, and is dependent on students' motivation, metacognition, and self-regulation with regards to a learning task. Few studies have addressed the aspects of engineering learning environments that promote the development of self-directed learning abilities. The goal of this study was to identify relationships between students' perceptions of their self-directed learning ability and their learning motivation within a project-based learning environment. Junior engineering students in a test cohort with heavy emphasis on project-based learning completed surveys on self-directed learning aptitude and learning motivation. Responses were compared with a quasicontrol group of junior students in traditional learning environments. Results show that the test cohort scored significantly higher on two types of motivation (intrinsic and identified regulation) that correlated strongly with students' use of self-regulated learning strategies.
\end{abstract}

Index Terms - Motivation, project-based learning, self-directed learning.

\section{INTRODUCTION}

Self-directed learning is a process in which students initiate, monitor, and reflect on their own learning, and it is an important element of life-long learning, an important and challenging outcome for engineering education. According to Pintrich and DeGroot [1] self-directed learning is driven by several primary elements: motivation to learn, cognitive strategies, metacognitive strategies, and persistence. The same authors have shown that intrinsic forms of motivation are strongly correlated to self-regulation among K-12 populations [1].

Classroom environments that support this mode of learning shift the responsibility of the instructor from that of the bearer of knowledge to that of a guide. Problem-based learning modes offer excellent opportunities to improve on students' self-directed learning skills. Such learning modes have been shown to support higher levels of intrinsic motivation and self-regulation among K-12 populations [2].

Despite these findings, little work has been completed to date on the effectiveness of various teaching pedagogies on self-directed learning in engineering education. Therefore, the purpose of this study was to compare self-directed learning readiness and learning motivation scores for a test group of engineering undergraduates exposed to a project-based learning environment and a quasi-control group of engineering undergraduates enrolled in more traditional courses.

\section{STUDY DESIGN}

We focused on individual's self- perceptions as they pertain to two primary latent constructs: self-directed learning readiness and learning motivation. Data was collected from a test group of 36 students in a 10-week junior-level materials engineering course (MATE 340/360). The course met five days per week for a total of 12 hours per week. The primary goal of the course was to strengthen students' self-directed learning and design skills through a project-based learning approach. In addition, there were specific learning outcomes for physical metallurgy and electronic properties of materials. Approximately $90 \%$ of class time was devoted to team-based projects focused on the design and testing of a cast metal product and fiber optic measurement system.

As part of summative assessment at the end of the quarter, students completed three surveys to measure their selfperceptions regarding self-directed learning and learning motivation. Perceptions regarding self-directed learning were measured using two instruments: the Competencies of SelfDirected Learning Scale (CSDL) [3], and the Self-Directed Learning Perceptions Scale (SDLPS) [4]. Together these instruments assess students' readiness to direct their own learning and to make use of available learning resources. Both instruments were modified to modernize language and make them more suitable for a college aged population. Learning motivation was assessed using the well-validated Situational Intrinsic Motivation Scale (SIMS) developed by Guay, Vallerand, and Blanchard [5].

A random group of 33 juniors from engineering departments outside materials engineering were included in the study as a quasi-control group for the SIMS scale only.

\section{RESULTS}

\section{Factor Analysis}

The CSDL and SDLPS instruments were analyzed with exploratory factor analysis to identify underlying factor structures among the items in the survey. All factors with eigenvalues greater than 1.0 were included in the final

\footnotetext{
${ }^{1}$ Trevor S. Harding, Materials Engineering, California Polytechnic State University, tharding@calpoly.edu

${ }^{2}$ Linda Vanasupa, Materials Engineering, California Polytechnic State University, lvanasup@calpoly.edu

${ }^{3}$ Richard N. Savage, Materials Engineering, California Polytechnic State University, rsavage@calpoly.edu

${ }^{4}$ Jonathan D. Stolk, Engineering, Olin College, Jonathan.Stolk@olin.edu 
analysis. Factor analysis failed to identify recognizable underlying constructs in either of the self-directed learning scales. Consequently, for each instrument, all item scores were averaged to generate a single score/index for the survey. Internal consistency was high for both the CSDL and SDLPS scales $(\alpha=0.92$ and 0.90 respectively). Further, the correlation between the two scales was high $(\mathrm{r}=0.62)$ indicating good convergent validity of the instruments.

The SIMS instrument was analyzed with confirmatory factor analysis as the underlying factor structure had been previously identified and validated by the developers [5]. This structure consists of four sub-scales: intrinsic motivation, identified regulation, external regulation, and amotivation. Intrinsic motivation is the tendency of an individual to engage in a behavior simply for the enjoyment of the activity. Identified regulation is the tendency of an individual to value a behavior for its enjoyment, but also to choose the behavior as a means of achieving a personal goal (e.g., skill development). External regulation refers to behavior that is undertaken either to gain external awards (e.g., high grades) or to avoid external punishments (e.g., low grades). Finally, amotivation is the tendency to engage in behaviors even when the individual sees no purpose in them. The first two motivational profiles may be seen as more internally-oriented on the self in comparison to external regulation and amotivation. All sub-scales were confirmed for this data set. Sub-scale scores were generated based on weighted sums of the item scores using the factor loadings as item weights. Cronbach's alpha for all sub-scales was 0.71 or greater.

\section{Comparison of Motivation Scores}

Students in the test group scored statistically higher on both the intrinsic motivation $(t=3.627, d f=67, p<0.001)$ and identified regulation $(\mathrm{t}=2.218, \mathrm{df}=67, \mathrm{p}=0.03)$ sub-scales of the SIMS survey compared to the quasi-control group. The effect size for the difference in intrinsic motivation was high $(\mathrm{d}=0.86)$; however, the effect size for the identified regulation scores was more moderate $(\mathrm{d}=0.53)$. No significant differences were found for the external regulation and amotivation sub-scales.

These results suggest that students enrolled in the projectbased learning course viewed their learning as driven more by their own personal curiosity, and to a somewhat lesser extent as a means of achieving a personal goal, as compared to the quasi-control group. However, both groups were equally likely to pursue course learning goals as a means of attaining high grades/avoiding low grades (i.e., external regulation), or to pursue course learning goals despite seeing no purpose behind them (i.e., amotivation). It would seem that the project-based learning environment successfully promotes more internally-oriented motivational preferences, but has little effect on altering more externally-oriented preferences.

\section{Correlations between Motivation and Self-Directed Learning}

For students in the test group, intrinsic motivation was highly correlated to both the CSDL scale $(r=0.572, p<0.001)$ and the
SDLPS scale $(\mathrm{r}=0.614, \mathrm{p}<0.001)$. Likewise, identified regulation was strongly correlated to both the CSDL scale $(\mathrm{r}=0.482, \mathrm{p}<0.01)$ and the SDLPS scale $(\mathrm{r}=0.622, \mathrm{p}<0.001)$. Taken together these results suggest that students who value learning for its own sake, or as a means of achieving personal goals, generally perceive themselves as better able to direct their own learning.

There were also somewhat weaker negative correlations between amotivation and self-directed learning. Students who reported a high sense of amotivation tended to report being less able to direct their own learning as measured by both the CSDL $(r=-0.345, p<0.05)$ and SDLPS $(r=-0.578, p<0.01)$ scales. Finally, there was no correlation between externally regulated students and their self-directed learning scores, suggesting that highly grade motivated students perceive themselves as no more ready for self-directed learning than non-grade motivated students.

\section{IMPLICATIONS}

The results of this study show that project-based learning does not change students' grade-oriented motivations; however, it does appear to cause students to be more focused on learning as a means of furthering their personal growth. In addition, the strong correlations found between self-directed learning and more internally-oriented motivational profiles (i.e., intrinsic motivation and identified regulation) suggest that these particular forms of motivation are critical elements of self-directed learning. Further, it would seem that traditional courses are promoting more externally regulated behavior which was not correlated with self-directed learning in this study. These findings imply that new pedagogical methods, such as project-based learning, are needed if life-long learning outcomes are to be positively addressed in engineering education.

\section{ACKNOWLEDGMENTS}

This material is based upon work supported by the National Science Foundation under Grant No. EEC-0530760.

\section{REFERENCES}

[1] Pintrich, P.R. and DeGroot, E.V., "Motivational and Self-Regulated Learning Components of Classroom Academic Performance", Journal of Educational Psychology, Vol. 82, No. 1, pp. 33-40, 1990.

[2] Sungur, S. and Tekkaya, C., "Effects of Problem-Based Learning and Traditional Instruction on Self-Regulated Learning", The Journal of Educational Research, Vol. 99, No. 5, pp. 307-317.

[3] Knowles, M.S. Self-Directed Learning: A guide for learners and teachers, Chicago: Folett Publishing Company, 1975.

[4] Pilling-Cormick, J., "Transformative and Self-Directed Learning in Practice", in New Directions for Adult and Continuing Education, 1997, pp. 69-77.

[5] Guay, F., Vallerand, R.J., and Blanchard, C., "On the Assessment of Situational Intrinsic Motivation and Extrinsic Motivation: The Situational Intrinsic Motivation Scale (SIMS)", Motivation and Emotion, Vol. 24, No. 3, 2000, pp. 175-213 